\title{
Transitional Zone of the Prostatic Parenchyma
}

National Cancer Institute

\section{Source}

National Cancer Institute. Transitional Zone of the Prostatic Parenchyma. NCI

Thesaurus. Code C33803.

The zone of the prostatic parenchyma that surrounds the proximal urethra. 